\title{
Impact of Sheetali and Sheetkari Pranayama on the Topographic Mapping of the Brain Waves
}

\author{
J. Thanalakshmi ${ }^{1}$, R. Ravindran ${ }^{2}$, Sembulingam $\mathrm{K}^{3}$ and Prema Sembulingam ${ }^{4}$ \\ ${ }^{1 .}$ Tutor in Physiology, Madha Medical College \& Research Institute, Kundrathur Main Road, Kovur, \\ Thandalam near Porur, Chennai - 600 122, Tamil Nadu, India. \\ 2. Reader, Dr. ALM PG Institute of Basic Medical Sciences, University of Madras, Tharamani Campus, Chennai \\ - 600 113, Tamil Nadu \\ 3. Professor of Physiology, Madha Medical College \& Research Institute, Kundrathur Main Road, Kovur, \\ Thandalam near Porur, Chennai-600 122, Tamilnadu, India, \\ 4. Professor of Physiology, Madha Medical College \& Research Institute, Kundrathur Main Road, Kovur, \\ Thandalam near Porur, Chennai - 600 122, Tamilnadu, India,
}

\begin{abstract}
Pranayama is yogic breathing technique which is known to improve the physical and mental well-being. The tremendous impact of yoga on the functioning of nervous system, attenuation of stress and promotion of relaxation is well known. Sheetali and Sheetkari pranayama also produce similar effects but, in addition, they also cool down the body and the brain. However, the impact of these pranayama on electroencephalogram (EEG) is not explored so far. For this study, 20 male volunteers were recruited and divided into two equal groups namely yoga group $(Y G)$ who underwent the practice of these pranayama for two months and non-yoga group (NYG) who did not do any type of breathing technique. In both the groups, EEG topographic mapping was recorded and the results were compared. The mapping revealed an increase in the delta (red bands) and alpha band power (green bands) in the frontal and occipital regions and an increase in theta band power (yellow bands) in the frontal region with a marked decrease in beta band power (blue bands) almost throughout the entire hemisphere after two months' of Sheetali and Sheethkari pranayama practice indicating that the brain (mind) was calm and quiet in relaxed state with less anxiety.
\end{abstract}

KEY WORDS: Yoga, Sheetali and Sheetkari Pranayama, Electroencephalogram, Topographic mapping, Brain waves, Band power,

\section{INTRODUCTION}

Yoga and meditation are the two unique gifts to human beings for maintaining healthy life by natural way. They enforce not only physical well-being but also mental well-being [1]. Physical well-being can be assessed by clinical methods whereas mental health is assessed subjectively by their behavior and objectively by recording the electrical activity of the brain in the form of electroencephalogram (EEG). EEG is a multiple digitized channel recording of brain waves that indicates the brain functional status, thanks to German Psychiatrist Hans Berger who is responsible for the introduction of the term EEG [2]. EEG can be used on a normal subject to find out the basic quality of the person ie, whether he is calm and quiet or anxious and aggressive by nature. If the person is anxious and aggressive, he shows exaggerated response even for a simple provocation. If this continues, cumulative effect of this may make the person to end up with psychiatric problem. If this nature is diagnosed earlier, consequences can be avoided by various methods like counseling, medication, yoga etc. Fortunately, identification of the problem is possible by recording EEG [3]..

EEG is also useful in identifying some neurological problems like epilepsy. However, a new technique had evolved from EEG called EEG brain topography in which the activity level of different brain areas is mapped out. It is not commonly used for recording simple basic EEG. It is called for some special cases like diagnosis of brain tumors and neurological disorders like epilepsy, arteriovenous mal-formations, stroke, narcolepsy, coma, withdrawal effects of psychoactive drugs and infectious diseases of the brain like meningitis [4]. In psychiatry also EEG Brain Mapping is valuable in identifying disorders of biological origin like schizophrenia, dementia, depression, brain atrophy, attention deficit disorders in children etc. [4].

EEG Brain mapping technique is now extended to the field of yoga and meditation also.The claim of the yoga teachers and yoga specialists that yoga and meditation modifies and refines the brain function is authenticated by this technique. It was found that Vipassana meditation increased the activity of anterior cingulate cortex, frontal cortex and prefrontal cortex [5] whereas Zen meditation increased the activity of 
cingulate cortex and frontal cortex [6]. Chiesa and Seretti were also of the same opinion after reviewing many articles but wanted these facts to be proved by further analysis [7]. Lutz et al were also in accordance with this fact but they found it in the emotion-based "compassion meditation" brain where heightened activity was noticed not only in cingulate gyrus but also in amygdala, tempero-pareital junction and right posterior superior temporal sulcus [8].

Practice of yoga has tremendous impact on the functioning of nervous system; it attenuates stress by promoting relaxation and increases the cognitive abilities like attention [9]. Pranayama is a part of yoga concerned with breathing technique. It claims to eliminate toxins from the body and maintain good health [10]. There are different types of Pranayama like Ujjai, Vastrika, Vibhagha, Nadi Sodhana, Nadi shuddi, Savithiri, Kapalabhati, Pranakarshan, Sheetali and Sheetkari Pranayama [10]. The effect of Pranakarshan Pranayama on altering the EEG brain waves according to the level of consciousness of the subject were reported recently [11]. Bhramari Pranayama was found to produce high frequency biphasic paroxysmal gamma waves which might resemble epileptic recordings but examination of the brain functional status proved it to be non-epileptic [12]. Yoga nidra, another form of yoga was found to induce mental relaxation by reducing anxiety level which was indicated by the well-formed alpha waves [11,13,14]. However, to the best of our knowledge, the effect of Sheetali and Seetkari pranayama on EEG mapping is not explored so far. Hence this study was taken up.

\section{MATERIALS AND METHODS}

20 male volunteers in the age group of 20-26 years were recruited from in and around Tharamani area in Chennai. They were divided into two groups namely non-yoga group (NYG) and yoga group (YG). YG subjects were recruited from the Government Yoga and Naturopathy Medical College in Arumbakkam at Chennai. NYG subjects were recruited from the student population of Institute of Basic Medical Sciences (IBMS), Tharamani in Chennai. All the participants were non-athletic, non-exercising and non-yogic subjects. All were normal healthy subjects without any history of allergic disorders, respiratory disorders, systemic diseases, cardiovascular diseases and neurological disorders. None of them were under any kind of medication. Ethical clearance was obtained from the institutional ethical committee. Informed consent was obtained from each subject after explaining the procedure and giving the assurance that they could withdraw from the study whenever they wanted.

YG was asked to assemble in the Department of Physiology at the IBMS. A brief introduction was given to them about Sheetali and Sheetkari pranayama and the procedure to perform them was demonstrated by Dr. K. Kanimozhi, the trained yoga teacher. They were asked to do these two pranayama in front of the instructor to make sure whether the participants learnt the procedure properly. Then they were instructed to practice these twice in a day, morning and evening, for two months. Periodically they were supervised by Dr. K. Kanimozhi and Dr. Mahesh Kumar (yoga practitioner in IBMS) to ensure the validity of the practice. After two months, the subjects were instructed to report in the Research Laboratory in the Department of Physiology and EEG recording was done. NYG was instructed to report in the same laboratory and EEG was recorded for them also.

\section{Procedure for Pranayama}

Getting ready for Pranayama : Participants were instructed to sit in padmasana position (cross-legged on the floor with the feet on the thighs and the soles facing upwards) with relaxed body and erect spine. The hands were to be kept on the knees in Gyan Mudra Posture (the tips of the index fingers to be joined to the tips of the thumbs while keeping the other fingers extended and loose). Eyes were to be closed gently. Body and the mind were to be relaxed for 2 minutes $(\mathrm{min}$ ) followed by 3 min of normal breathing before starting the procedure.

\section{Sheetali pranayama (Fig 1)}

- The participants were asked to extend the tongue outside the mouth as far as possible without strain and roll the sides of the tongue up so that it would form a tube. They were instructed to inhale through the tube for 4 seconds (sec) with opened eyes. The inhalation was done with the hissing sound like................c and they were instructed to concentrate on the coolness developed on the tongue and roof of the mouth

- At the end of inhalation, the tongue was drawn in, mouth was closed and exhalation was done through the nose. They were asked to feel the coolness of the breath penetrating into the brain and spreading out into their entire nervous system.

- Initially inhalation was done for $4 \mathrm{sec}$ and exhalation was done for $6 \mathrm{sec}$ (4:6). Slowly with practice they were instructed to increase the counts to $4: 8$, or $5: 10$ or $6: 12$.

- This was continued for 5 minutes ( $\mathrm{min}$ ) which was considered as one round of Sheethali pranayama. This was followed by $1 \mathrm{~min}$ rest. 
- This 5 min Sheetali pranayama with one min gap was repeated two more times and at the end of this, 3 min rest was followed. Altogether this one round was spanned for $20 \mathrm{~min}$ [15].

This was followed by Sheetkari pranayama.

\section{Sheetkari pranayama}

Participants continued Sheetkari pranayama in the same posture with relaxed body and erect spine

- $\quad$ They were asked to open the lips and bring the teeth together lightly.

- They were instructed to take a long deep inhalation through the gap between the teeth.

- At the end of inhalation, the chin was lowered to the chest and the breath was held for 6 sec without making any impact on the quality and depth of the following exhalation.

- Then the chin was lifted up, the right nostril was closed with the right thumb and exhalation done slowly through the left nostril. This completed one round.

- This was repeated for three rounds in 20 min duration

- At the end, breathing was brought back to normal $[15,16]$

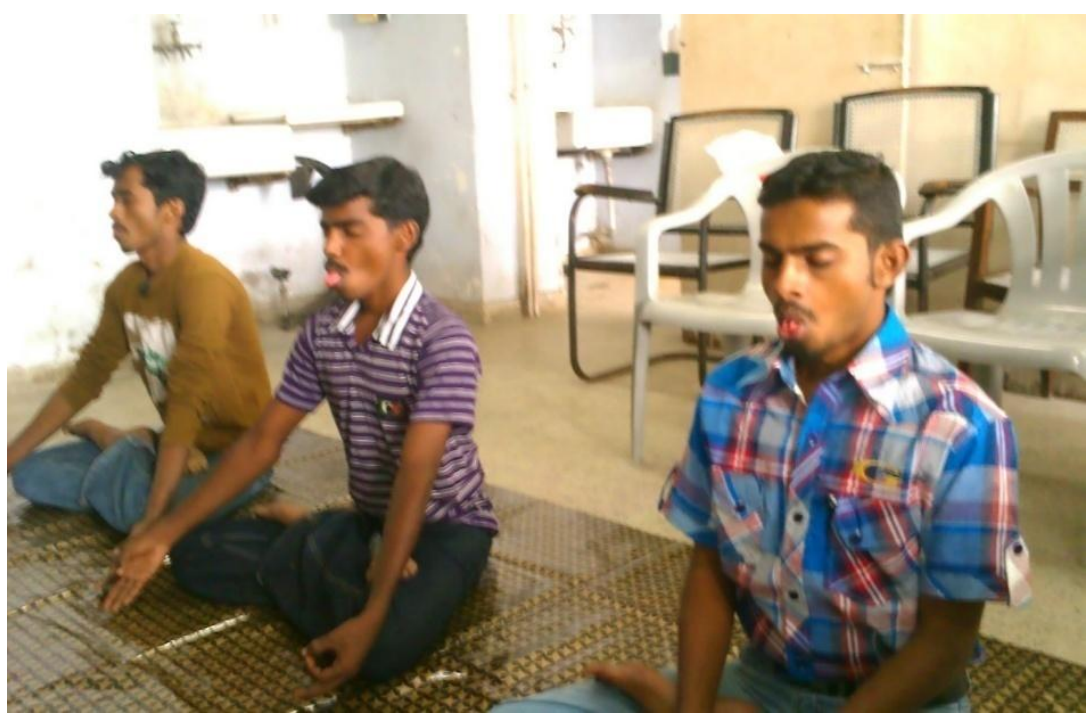

Fig. 1. Performance of Sheetali Pranayama

\section{Recording of EEG:}

EEG was recorded by using Recorder Medicare System (RMS) - Model "Brain View Plus". The instrument was standardized and calibrated. The subjects were seated in a chair comfortably. Then, nineteen active electrodes viz, FP1, FP2, F7, F3, FZ, F4, F8, T3, C3, CZ, C4, T4, T5, P3, PZ, P4, T6, O1 and O2 were placed on the scalp and two inactive electrodes were placed on right and left ear lobes. The odd numbered recording electrodes were placed on the left side of the scalp while even numbered electrodes were placed on the right side of the scalp (Fig 2) in a fashion of geometrical array. Before the recording was started, the subjects were instructed to look straight in front of them, even with closed eyes and not to make any unnecessary movements to avoid artifact in the EEG signals.

\section{Data acquisition :}

The activity of the brain was recorded by special software inside the computerized apparatus on a color screen. The raw EEG signals were amplified and band pass filtered in the $0.5-30 \mathrm{~Hz}$ frequency range and digitized at a sampling rate of $128 \mathrm{~Hz}$. The impedance of the recording electrodes was maintained below $5 \mathrm{~K} \Omega$. By visual inspection the presence of an adequate EEG signals was determined. Only artifact free 1 min EEG recordings were selected for the analysis 


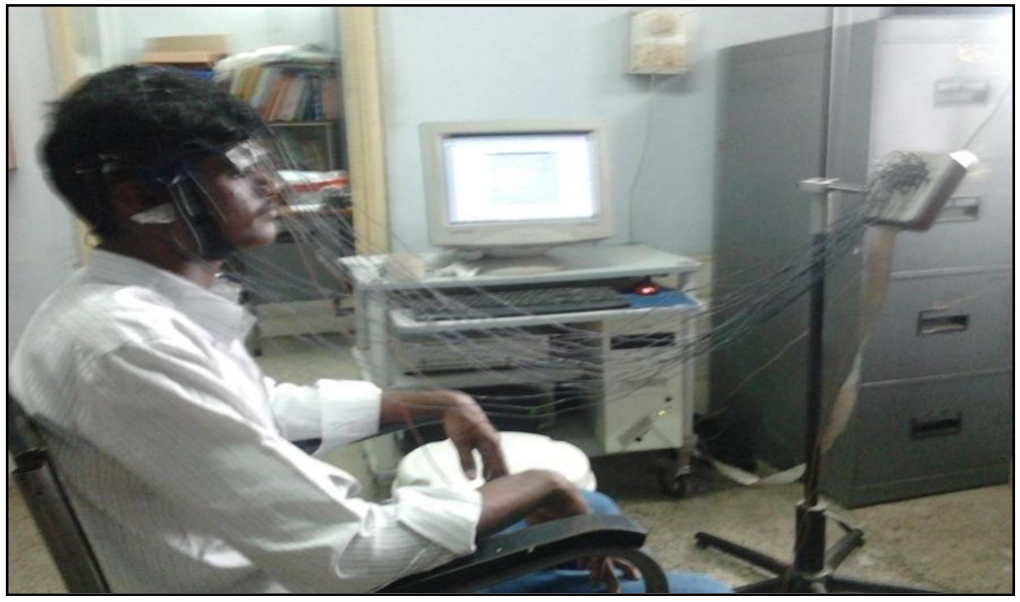

Fig 2. Placement of electrodes for recording EEG

\section{RESULTS:}

Analysis of EEG Mapping : In the topographic recordings, the level of activity was shown by different color shades. Generally black and blue colors represent low EEG frequency band power and yellow and red color indicates the larger EEG frequency band power [3, 17].

Yogic group: In YG, EEG topographic study showed an increase in the delta (red bands) and alpha band power (green bands) in the frontal and occipital regions and an increase in theta band power (yellow bands) in the frontal region. There was a marked decrease in beta band power (blue bands) almost throughout the entire hemisphere (Fig 3)

Non yogic group: In NYG, there was no theta or alpha band power (absence of yellow and green bands) and few delta waves were seen in frontal, central, and occipital regions (red bands) (Fig 4).

\section{DISCUSSION}

Our results showed that practice of Sheetali and Sheetkari pranayama is beneficial to the body and mind as indicated by the notable decrease in beta band power and increase in the alpha, delta and theta band power. Normally, beta band power is prominently seen in a highly focused, agitated and attentive brain as in cases of problem solving or in fear, anxiety etc. whereas alpha and delta bands are mostly seen in calm and quiet brain [18]. These two types of pranayama are claimed to cool the body and counter-act the Pitta and body heat by regulating the body temperature and modifying the functions of important areas of the brain. They also reduce the mental and emotional excitation by promoting the free flow of prana through the body [19, 20].

YG subjects in our study also showed a state of relaxation with decreased level of anxiety which was reflected by the presence of increased alpha band power and decreased beta band power. At the same time, their brains were deeply focused with higher level of mental consciousness as indicated by the increase in delta and theta band powers. This observation regarding the impact of Sheetali and Sheetkari Pranayama practice on topographic mapping of the brain is the first of its kind. There are reports in the literature regarding the impact of other types of pranayama on brain mapping: Vialatte et al found that Bhramari pranayama improvised the activity of the brain by producing "controlled high-frequency gamma waves" [12]; though gamma waves were concerned with epileptic episodes, the YG subjects of their study were normal ones without any symptom of epilepsy. Mangalteertham Sannyasi noticed that Yoga Nidra produced alpha dominance in the brain associated with mental relaxation [21]. In school children, a positive correlation was noticed between the long-time practice of Yoga Nidra and reduction in the stress and anxiety levels as revealed by the alpha level in EEG [13]. Barnwal Suresh Lal noticed increased alpha EEG in students who practiced Nadi Sodhan Pranayama [22]

According to Rachel Hanson, , pranayama increases both alpha and beta activity in the beginning of the practice, meaning that initially, it induces increased awareness and increased relaxation at a time.. Actually in day-to-day life, the beta activity decreases and alpha activity increases when the person is aware and awake with daily activity, and this pattern reverses when the person is relaxing and falling asleep. But pranayama increases both the types of brain activity, ie. making the person more alert and at the same time, more relaxed which is called as "ideal state of the mind" by Yogis [23]. Sheetali and Sheetkari Pranayama fall in this category giving all the 


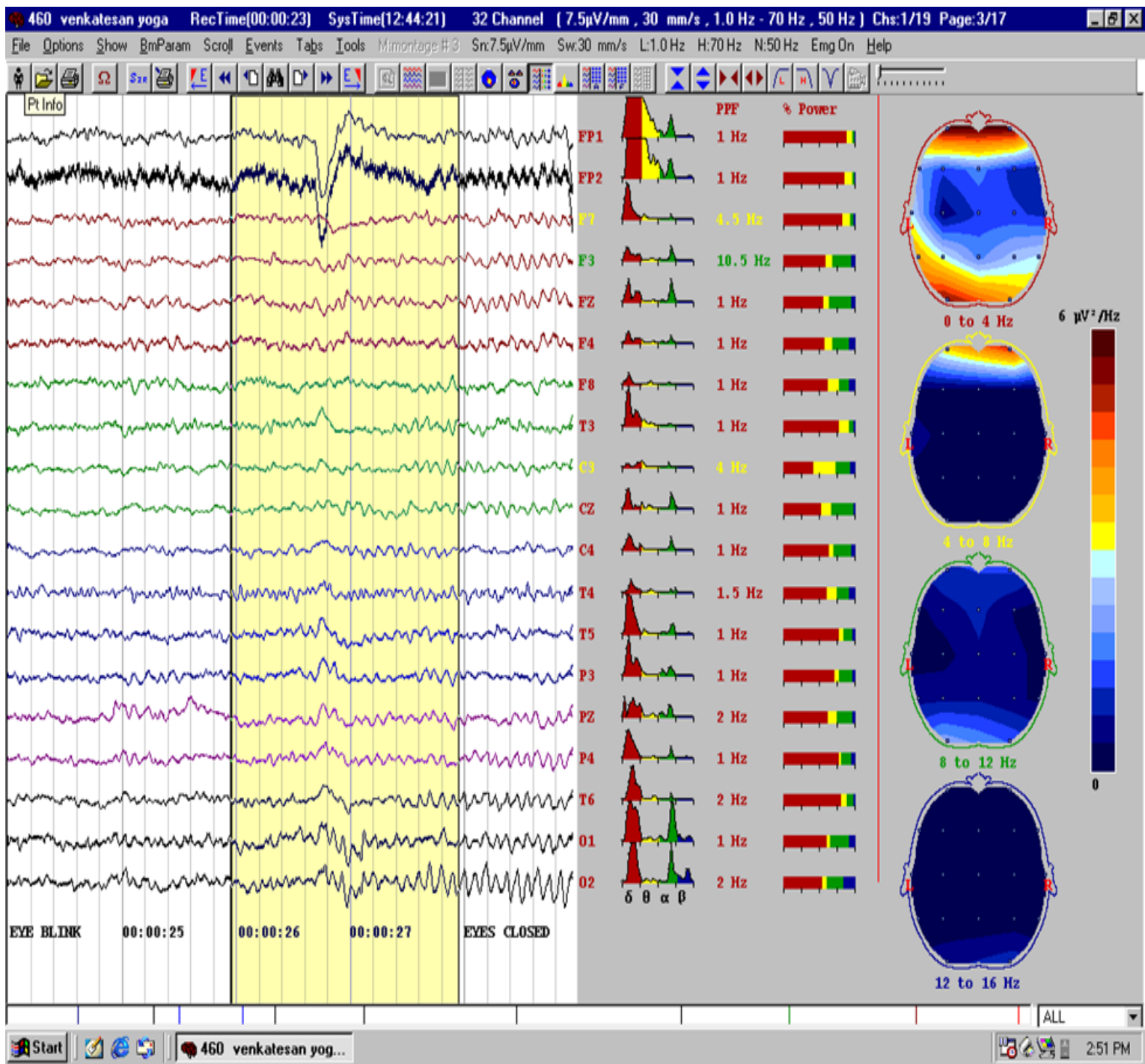

Fig. 3. Topographic mapping of brain activity in yoga subjects

primary advantages of deep breathing techniques like reducing the stress, controlling anger and irritation, combating restlessness and creating the feeling of tranquility and peace like any other type of pranayama as revealed by the topographic mapping of the brain activity. However, these two types of pranayama differ strikingly from other types in that they cool down the body and reduce the temperature of the brain as claimed by Swami Swatmaram. According to him, this cooling effect is the mechanism by which it decreases the bile, corrects the spleen disorders, controls hunger and thirst and calms down the entire nervous system [24]

Deboer and Tobler (1995) noticed that during sleep when the body temperature falls, slow frequency waves were produced and EEG theta frequency changes in parallel with euthermic brain temperature [25, 26]. Our results reaffirm these statements through the topographic mapping of the brain waves in YG, ie, Sheetali and Sheetkari pranayama produce slow frequency alpha, theta and delta waves which stand for calm and relaxed state.

\section{CONCLUSION}

Practice of Sheetali and Sheetkari pranayama is good to the body and mind and this is revealed by the notable decrease in beta band power and increase in alpha, delta and theta band power in various areas of the brain. EEG analysis was done on various types of pranayama but to the best of our knowledge, on Sheetali and Sheetkari pranayama, our study is the first of its kind. As it brings the cooling effect on the body and is easy to perform, it will be beneficial in tropical countries like India to abate the heat, and keep the body and the mind cool and calm. 


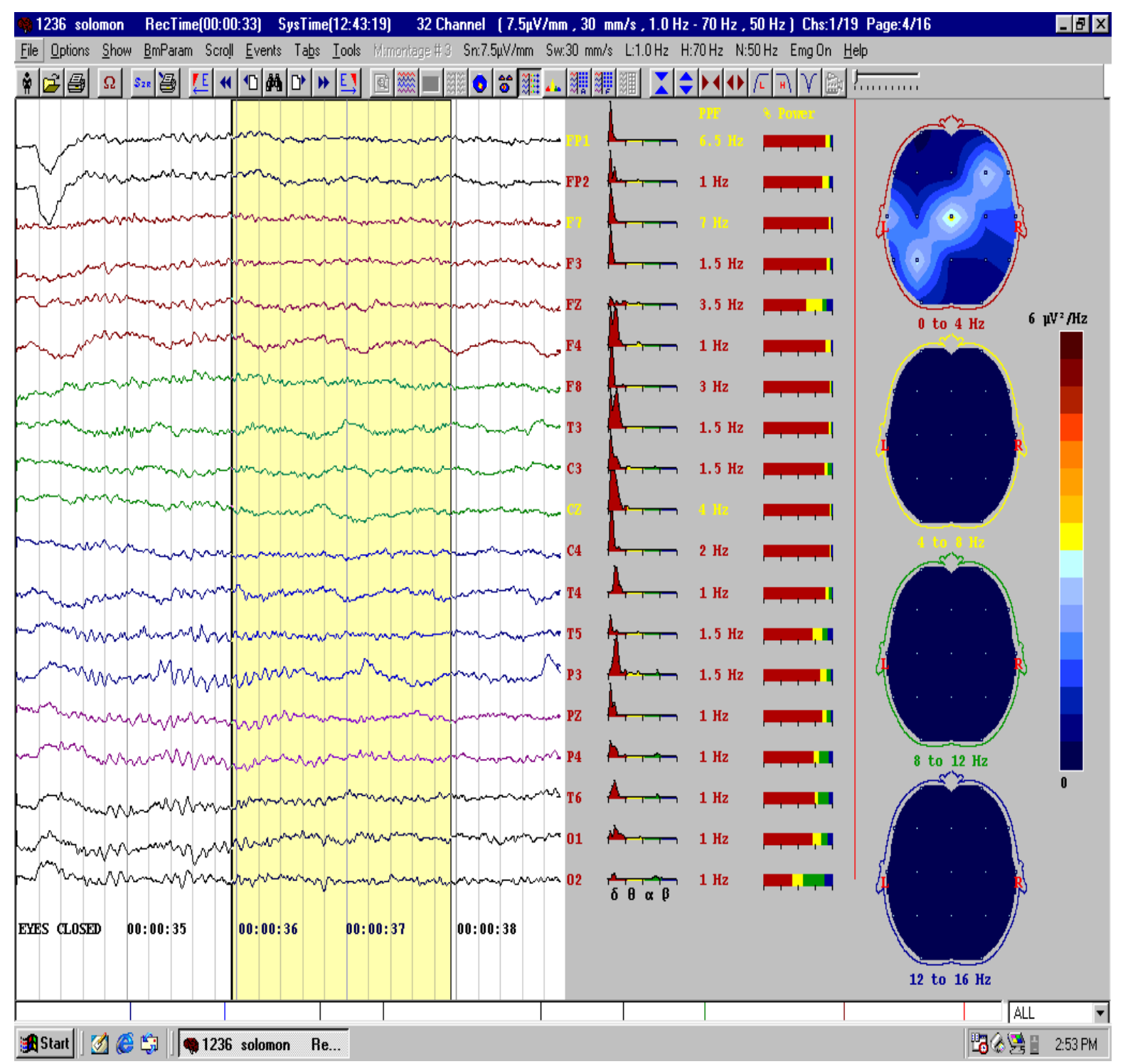

Fig 4. Topographic mapping of brain activity in non-yoga subjects

\section{Limitations in the present study}

* Comparison of topographic mapping in YG should have been done before and after the practice of Pranayama in the same subjects instead of comparing the YG and NYG

* Admittedly, the number of subjects was less

* Correlation between the frequency and amplitude of the EEG waves and the information derived from the topographic mapping may be an interesting interpretation with more reliable conclusions; and it is underway

Acknowledgement :The authors are deeply indebted to the Government Yoga and Naturopathy Medical College for providing the subjects for our study. We are also thankful to the Yoga Instructors Dr. K. Kanimozhi and Dr K. Mahesh Kumar for teaching the method of doing Sheetali and Sheetkari pranayama and supervising them periodically to ensure the validity of the practice. Our thanks are due to Mr. T. Lokeshwar, Yoga instructor, for his valuable suggestions of these two types of pranayama. 


\section{REFERENCES}

[1] http://hinduism.about.com/od/meditationyoga/

[2] J. D. Bronzino. 1995. Principles of Electroencephalography. In: J.D. Bronzinoed. The Biomedical Engeneering Handbook, pp. 201212, CRC Press, Florida

[3] Renato M.E. Sabbatini, PhD. Mapping the Brain. http://www.cerebromente.org.br/n03/tecnologia/eeg.htm

[4] Holzel BK, Ott U, Hempel H, Hackl A, Wolf K, Stark R, Vaitl D (2007). "Differential e"gagement of anterior cingulate and adjacent medial frontal cortex in adept meditators and non-meditators". Neuroscience Letters 421: 16-21. doi:10.1016/i.neulet.2007.04.074. ),

[5] Cahn BR, Polich J (2006). "Meditation states and traits : EEG, ERP, and neuroimaging studies". Psychological Bulletin 132 (2): 180-211. doi:10.1037/0033-2909.132.2.180. PMID 16536641. )

[6] Pagnoni G, Cekic M, Guo Y ("008). "“ Thinking about not- thinking': neural correlates of conceptual processing during Zen meditation". PLoS ONE 3: e3083. 10.1371/journal.pone.0003083.)

[7] Chiesa A, Ser"etti, A (2010). "A systematic review of neurobiological and clinical features of mindfulness meditations". Psychological Medicine 40 (8): 1239-1252.).

[8] Lutz A, Brefczynski-Lewi“ J, Johnstone T, Davidson RJ (2008). . PLoS ONE 3 (3): e1897. doi:10.1371/journal.pone.0001897.

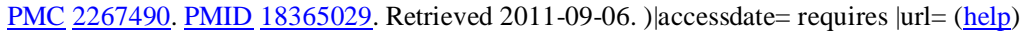

[9] Madanmohan 2008, Effect of yogic practices on different system of human body. Indian journal physiology and pharmacology; $52: 164-170$

[10] Swami Satyananda Sarawathi. 2005. Bihar school of yoga , Asana pranayama mudra bandha; Yoga publication Trust, Munger, Bihar, India, 1:10-12.

[11] Kamakhya Kumar \& Bhanu Joshi. 2009. Study on the effect of Pranakarshan pranayama and Yoga nidra on alpha EEG \& GSR. Indian Journal Of Traditional Knowledge Vol. 8(3), pp. 453-454

[12] Vialatte FB, Bakardjian H, Prasad R, Cichocki A. 2009. Conscious Cogn, 18 (4), 977-88. EEG paroxysmal gamma waves during Bhramari Pranayama: a yoga breathing technique

[13] Kumar Kamakhya. 2004. Yoga nidra and its impact on student's well being, Yoga Mimamsha, 36 (1\&2) (2004).

[14] Roney SM Dougal, Altered states of consciousness and yogic attainment in relation to awareness of precognitive and clairvoyant targets, (Psi Research Centre), 2001.

[15] http://www.yogicwayoflife.com /sheetali-pranayama-the-cooling-breath/

[16] Yoga with subhash. Yoga for total well-being. http://yogawithsubhash.com/2010/09/15/sheetali-seetkari-pranayama-Cooling pranayama to Control Stress and Blood Pressure

[17] http://www.yogameditation.com/ Articles/Issues-of-Bindu/Bindu-12/Mapping-the-brains-activity-after-Kriya-Yoga Erik Hoffmann, Mapping the brains activity after Kriya Yoga)

[18] K. sembulingam and Prema Sembulingam 2013. Essentials of Medical Physiology, Sixth Edition. JAYPEE Brothers Medical Publishers (P) Ltd. New Delhi. 920-930)

[19] http://anmolmehta.com/blog/2007/10/11/sheetali-pranayama-breathing-exercise-for-stress-anger-management/.Sheethali Pranayama Breathing Exercise for Stress \& Anger management - Posted in Ayurveda, Emotional Mastery, Yoga Pranayama by Anmol Mehta

[20] Ruchi Renavikar. http://total-yoga.org/portfolio-items/sheetkari-pranayam/ Sheethkari pranayama.

[21] Mangalteertham Sannyasi. 1998. Yoga nidra-altered state of consciousness, In: Yoga Nidra, edited by Swami Satyananda, 6th edition, Bihar School of Yoga, Munger

[22] Barnwal Suresh Lal and Kulshrestha Asim . 2011. The Impact of Nadisodhan Pranayama on Alpha EEG Quest-The Journal of UGC-ASC Nainital. Volume 5, Issue 2. 284-287 (Online published on 22 November, 2011)

[23] Rachel Hanson. http:// yoga.lovetoknow.com/Pranayama_Brain_Studies

[24] Rishi Dharmachandra. Yoga point. Official Site of Yoga Vidhya Gurukul (University) http://www.yogapoint.com/pranayama/sheetali.htm].

[25] Deboer T, Tobler I. 1995. Temperature dependence of EEG frequencies during natural hypothermia. Brain Res 670(2): 153-6

[26] Deboer T. 2002. Electroenphalogram theta frequency changes in parallel with euthermic brain temperature. Brain Res. 930 (1-2): $212-5$ 